\title{
Dairy cow preference and usage of an alternative freestall design
}

\author{
C. C. Abade, ${ }^{*} \dagger$ J. A. Fregonesi, ${ }^{\star} \dagger$ M. A. G. von Keyserlingk, ${ }^{*}$ and D. M. Weary ${ }^{* 1}$ \\ *Animal Welfare Program, Faculty of Land and Food Systems, University of British Columbia, 2357 Main Mall, Vancouver, British Columbia, \\ V6T 1Z4, Canada \\ †Cuidado Animal e Responsabilidade Ética (CARE), Universidade Estadual de Londrina, Paraná, CEP-86057-970, Brazil
}

\begin{abstract}
Freestall housing for dairy cows was created to reduce the amount of bedding and labor needed to keep stalls clean. However, some aspects of stall design may restrict stall usage by cows. The aim of this study was to assess dairy cow preference and usage of a conventional stall (with a neck rail and metal stall dividers) and an alternative stall design with no neck rail or stall dividers other than a wooden board protruding slightly (8 $\mathrm{cm})$ above the lying surface. In the no-choice phase of the study, 48 cows were randomly assigned to 8 groups (of 6 cows each); groups were alternately allocated to the 2 treatments. Each group was observed for $7 \mathrm{~d}$ on one treatment and then switched to the alternate treatment for $7 \mathrm{~d}$. For the choice phase (also $7 \mathrm{~d}$ ), groups in adjacent pens were merged (to form 4 groups, each with 12 cows) and cows had free access to both treatments within the merged pen. In the no-choice phase, cows spent more time standing with 4 hooves in the alternative versus conventional freestall $(0.60 \pm 0.06 \mathrm{vs}$. $0.05 \pm 0.06 \mathrm{~h} / \mathrm{d}$ ), but stall designs had no effect on time spent lying down $(13.2 \pm 0.4$ vs. $12.9 \pm 0.4 \mathrm{~h} / \mathrm{d})$. In the choice phase, cows spent more time lying down in the conventional freestall $(9.4 \pm 0.8$ vs. $4.1 \pm 0.8 \mathrm{~h} / \mathrm{d})$ and more time standing with all 4 hooves in the alternative stall $(0.24 \pm 0.03$ vs. $0.02 \pm 0.03 \mathrm{~h} / \mathrm{d})$. These results illustrate how different stall design features can affect different types of stall use; the more open design facilitated standing fully in the stall, but the protruding partitions likely made the stall less suitable for lying.
\end{abstract}

Key words: cow comfort, preference test, barn design, welfare

\section{INTRODUCTION}

Conventional freestalls in dairy barns include stall partitions, neck rails, and other design features intended to minimize the likelihood that cows will defecate

Received June 25, 2014.

Accepted October 29, 2014.

${ }^{1}$ Corresponding author: danweary@mail.ubc.ca and urinate in the stall. For this reason, freestall barns typically require less bedding (Schmisseur et al., 1966) and less time to maintain the stall surface (Fregonesi et al., 2009a) than open pack systems. Freestall design features help to maintain stall cleanliness. For example, narrow stall partitions (Tucker et al., 2004), the presence of a brisket board (Tucker et al., 2006), and restrictive neck rail positioning (Bernardi et al., 2009; Fregonesi et al., 2009a) all reduce the risk of cows soiling the stall.

However, these same design features may also have unintended effects on the cow's ability to use the stall. For instance, restrictive neck rail placements prevent cows from standing in the stall (Tucker et al., 2005; Fregonesi et al., 2009a). This, in turn, appears to increase time spent standing fully or partially outside of the stall, increasing the risk of lameness (Bernardi et al., 2009). Similarly, narrow stall partitions (Tucker et al., 2004) and the presence of a brisket board (Tucker et al., 2006) can both reduce the time cows spend lying down in freestalls.

Current stall designs thus seem to leave producers with 2 imperfect options: restrictively configured stalls that help maintain a relatively clean stall surface and lower stall maintenance costs, or less-restrictive configurations that may improve cow comfort and reduce the risk of lameness. Research to date has either compared different configurations of traditional freestalls (e.g., by moving stall partitions to vary stall width; Tucker et al., 2004) or compared freestalls with open packs (Fregonesi and Leaver, 2002). Little research has compared freestalls with alternative stalls that still guide the cow's lying position but do so with less reliance on design features that are known to interfere with stall use.

The aim of the current study was to compare a conventional freestall with an alternative design that did not include a neck rail or side partitions. Individual lying spaces were instead created using wooden boards that protruded above the stall surface. We predicted that cows would prefer these less restrictive stalls, spending more time lying down and more time standing in these stalls. 


\section{MATERIALS AND METHODS}

The experiment was conducted at the University of British Columbia's Dairy Education and Research Centre in Agassiz, British Columbia, Canada. Forty-eight mid-lactation Holstein cows were randomly assigned to 8 groups of 6 animals each. Groups were balanced based on average (mean $\pm \mathrm{SD})$ parity $(3 \pm 1.6$ lactations), DIM (165 $\pm 43 \mathrm{~d})$, BW $(700 \pm 85 \mathrm{~kg})$, body height (149 $\pm 4.1 \mathrm{~cm}$; measured at the third thoracic vertebra), body length $(201 \pm 10 \mathrm{~cm}$; measured between the first cervical and the most caudal vertebra at the base of the tail), and BCS ( $3 \pm 0.3$; scored from 1 to 5 following Edmonson et al., 1989). Before the experiment, cows were gait scored (from 1 to 5 following Flower and Weary, 2006); all cows with gait score $>3.0$ were excluded and the groups were balanced to have equal number of cows with gait score 2.0, 2.5, and 3.0.

Cows were housed in 4 pens in a naturally ventilated wood-frame freestall barn with curtained sidewalls. Each of the pens $(7.5 \times 13.5 \mathrm{~m})$ contained 12 stalls configured in 3 rows, 2 rows facing one another and the back row facing a cement wall (Figure 1). Conventional pens were equipped with stalls divided by Dutch-style partitions. The stalls in the alternative pens were divided using wooden boards buried in the sand and protruding $8 \mathrm{~cm}$ above the bedding.

Cows were fed ad libitum a TMR consisting of $22.3 \%$ grass silage, $16.6 \%$ corn silage, $49.4 \%$ concentrate mix, and $11.7 \%$ alfalfa hay. Fresh feed was provided twice daily (0600 and $1500 \mathrm{~h}$ ), and feed was pushed up 3 times per day. Water was freely available from a selffilling trough. Cows were milked twice daily (at 0600 and $1600 \mathrm{~h}$ ) in a double-12 parallel milking parlor.

\section{Experimental Design}

The 2 conventional and 2 alternative pens, with 12 stalls each, were arranged in a checkerboard fashion within the barn. In the first replicate of the experiment, 4 groups of 6 cows each were randomly assigned to the 4 test pens. Each group was initially tested in a $7 \mathrm{~d}$ no-choice phase; the first $4 \mathrm{~d}$ cows were allowed to habituate to the pen, and behaviors were recorded for the last $3 \mathrm{~d}$. Groups were than switched to the alternate treatment (in an adjacent pen) for a second 7-d period with behaviors again recorded during the last $3 \mathrm{~d}$. During the choice phase, adjacent pens (one alternative and one conventional) were merged creating a single large pen with 12 cows and 24 stalls, allowing free access to the 2 treatments. The choice phase was also $7 \mathrm{~d}$ with behavior recorded during the last $3 \mathrm{~d}$. Once this replicate was completed, the treatments were reversed (i.e., the conventional pens were reconfigured as alternative and vice versa) and 4 new groups of 6 cows each were assigned to the 4 test pens and tested in the no-choice phase. After that, the pens were merged again for the choice phase. In this way, we tested a total of 48 cows composed of 8 test groups in the no-choice phase and 4 test groups in the choice phase.

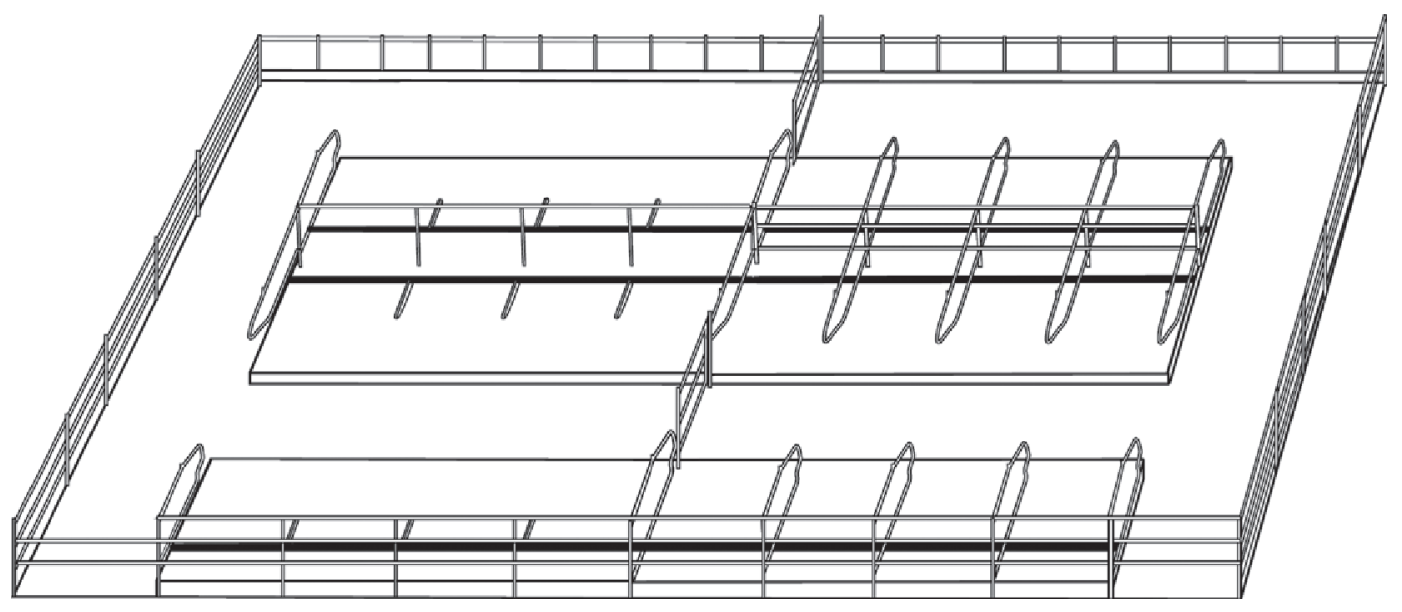

Figure 1. Layout of a conventional pen (right) and an adjacent alternative pen (left). Conventional pens used stalls with a bed length of 2.4 $\mathrm{m}$ divided by Dutch-style partitions measuring $1.2 \mathrm{~m}$ wide from center to center with the neck rail positioned at $1.1 \mathrm{~m}$ above the stall surface and $1.7 \mathrm{~m}$ from the inside of the rear curb. The brisket board (height $=0.1 \mathrm{~m}$ above the stall surface) was positioned $1.8 \mathrm{~m}$ from the inside of the curb. The curb was $0.2 \mathrm{~m}$ in height as measured from the floor of the alley. The stall was deep bedded with $0.3 \mathrm{~m}$ of washed river sand raked and cleaned every morning and afternoon milking. Flooring elsewhere in the pen was concrete and cleaned 6 times/d with automatic scrapers. The feed bunk measured $7 \mathrm{~m}$ and had a post-rail feeding barrier. Alternative pens were identically configured, except all stall partitions and the neck rail were removed, leaving only the posts used to secure the freestall partitions. Wooden boards $($ length $=80 \mathrm{~cm}$, height $=30$, and width $=5 \mathrm{~cm}$ ), also spaced $1.2 \mathrm{~m}$ wide from center to center, were butted against the brisket board and buried in the sand such that that $8 \mathrm{~cm}$ protruded above the bedding. 


\section{Behavior}

Behavior was recorded $24 \mathrm{~h} / \mathrm{d}$ using 2 cameras per pen (WV-CW504SP and WV-BP330, Panasonic, Osaka, Japan) positioned $6 \mathrm{~m}$ above each of the 8 pens. Red light bulbs $(100 \mathrm{~W})$ were hung $10 \mathrm{~m}$ above each experimental pen to facilitate video recording at night. Cows were marked with unique symbols using hair dye to allow individual identification. Instantaneous scan sampling at 5-min intervals was used to identify cows' positions in the stalls (lying, standing with 4 or 2 feet in the stall, or standing outside the bedded area) during the last $3 \mathrm{~d}$ of both experimental phases; these data were used to calculate the total time per cow spent in each of these activities. In addition, during the nochoice phase only, videos for 1 to $4 \mathrm{~h}$ after milking were scanned continuously to record the time cows required to transition from lying down to standing up and vice versa (following Lidfors, 1989).

\section{Stall and Udder Cleanliness}

Stall cleanliness was assessed using a $1.0 \times 1.6 \mathrm{~m}$ wire grid, containing 160 equally sized squares that were placed at the rear section of the stall closest to the alley and centered between the stall partitions. During the last $3 \mathrm{~d}$ of the no-choice phase, whereas cows were out of the stalls for milking, the total number of squares containing any visible fecal material were counted. Fecal matter on the udders of experimental cows was assessed when cows were in the parlor. Cleanliness was assessed using a subjective score from 1 to 4 , where 1 $=$ no manure present, $2=$ minor splashing of manure near the teats, $3=$ distinct plaques of manure on the lower half of the udder, and $4=$ confluent plaques of manure encrusted on and around the teats (Cook and Reinemann, 2007). Only the rear portion of the udder immediately visible to the milker was scored from the base of the teats to the rear quarter attachment.

The time required to remove fecal matter from the stall and to level the bedding with a rake was recorded during morning and afternoon milking on the last day of each no-choice phase (following Fregonesi et al., 2009a).

\section{Statistical Analysis}

The duration for each behavior recorded was averaged across the $3 \mathrm{~d}$ in each phase to form a mean value per cow for each treatment. For the no-choice phase cow behaviors were averaged for each group $(n=8)$ for each of the 2 treatments (conventional versus alternative stall) yielding a total of 16 observations. A mixed model (Proc Mixed, SAS, version 9.3, SAS Institute
Inc., Cary, NC), with the group specified as a random effect ( $7 \mathrm{df})$, was used to test the effect of treatment (1 df) against the residual error $(7 \mathrm{df})$.

For the choice phase analysis, the values were averaged to form one mean per choice group $(\mathrm{n}=4)$. Behaviors occurring in either the conventional or alternative freestall were recorded separately. A mixed model, with group specified as random effect (3 df), was used to test the effect of stall type $(1 \mathrm{df})$ against the residual error ( $3 \mathrm{df})$.

During the choice phase we expected that larger cows would most benefit from access to more open lying stalls. To test the effect of cow size, we subtracted the time each cow spent in the alternative stalls from time spent in the traditional freestalls and correlated these differences with measures of cow height and length using Pearson correlation. We predicted that larger cows would show a strong preference for the alternative stalls (i.e., a larger positive difference).

Udder and stall cleanliness scores and time to clean the lying areas were analyzed for the no-choice phase only. Values were averaged per pen per treatment and analyzed using a model with pen specified as a random effect $(3 \mathrm{df})$, to test the effect of stall type (1 df) against residual error (3 df).

\section{RESULTS}

\section{No-Choice Phase}

When cows were restricted to only one housing treatment, no difference was observed in time spent lying down in the alternative versus traditional freestalls, with cows averaging about $13 \mathrm{~h} / \mathrm{d}$ lying down in both treatments (Figure $2 ; F_{1,7}=1.35, P=0.28$ ). Cows averaged approximately $1.2 \mathrm{~h} / \mathrm{d}$ standing with just the front 2 hooves in the bedded area, again with no differences between treatments $\left(F_{1,7}=0.77, P=0.41\right)$. However, cows spent approximately $0.6 \mathrm{~h} / \mathrm{d}$ standing fully in the open stalls, and this behavior was almost never observed when cows were kept in the conventional freestalls $\left(F_{1,7}=44.71, P<0.001\right)$.

Cows tended to require less time to stand up in the alternative versus conventional freestall $(5.1 \pm 0.31$ vs. $\left.5.8 \pm 0.31 \mathrm{~s} ; F_{1,7}=3.87, P=0.09\right)$. The time to transition from standing to lying did not statistically differ between the 2 treatments $(5.9 \pm 0.21$ vs. $6.3 \pm 0.21 \mathrm{~s}$; $\left.F_{1,7}=2.63, P=0.15\right)$.

Pens configured with the alternative stalls had cows with dirtier udders (udder score $1.6 \pm 0.05$ vs. $1.3 \pm$ $\left.0.05 ; F_{1,3}=17.54, P=0.025\right)$, and the lying area surface had more fecal contamination $(4.2 \pm 0.3$ vs. $0.2 \pm$ 0.3 dirty squares/stall; $\left.F_{1,3}=77.45, P=0.003\right)$. The time required to maintain the stall surface tended to 


\section{a) Lying time}

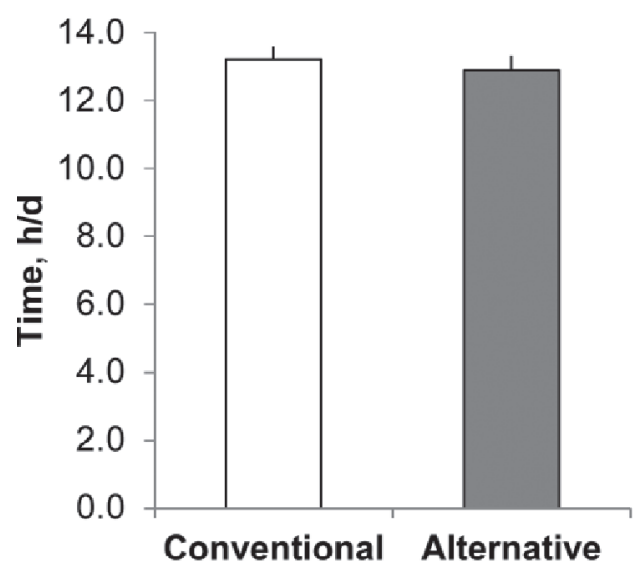

b) Standing - 2 hooves

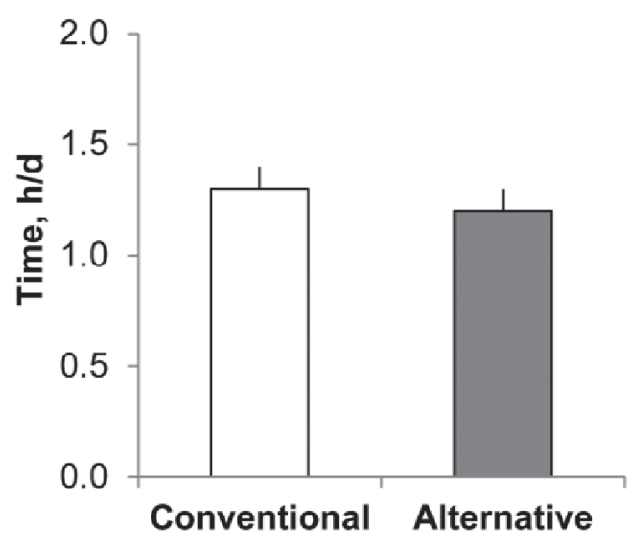

c) Standing - 4 hooves

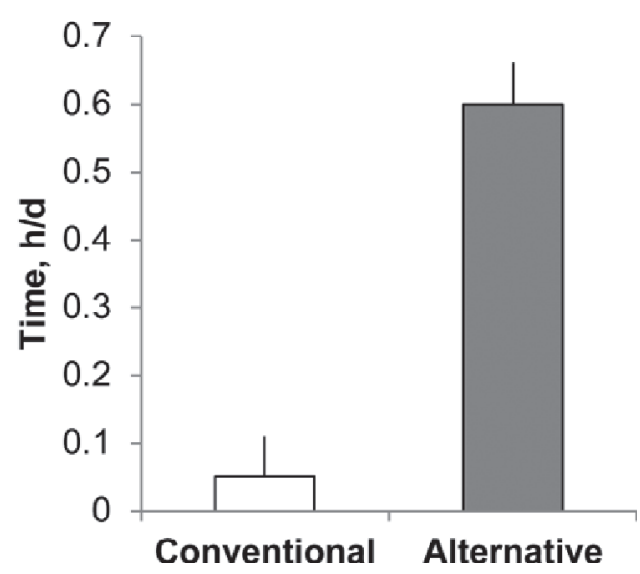

Figure 2. Results from the no-choice phase during which 8 groups of 6 cows each were restricted to pens with either conventional or alternative stalls for $7 \mathrm{~d}$ and then retested in the opposite treatment for a second 7 -d period. Least squares means $( \pm \mathrm{SE})$ are shown for time $(\mathrm{h} / \mathrm{d})$ spent (a) lying down in the stall, (b) standing with front 2 hooves in the stall, and (c) standing with all 4 hooves in the stall. be higher for the alternative versus conventional stalls $\left(3.25 \pm 0.35\right.$ vs. $2.15 \pm 0.35 \mathrm{~min} / \mathrm{pen} ; F_{1,3}=5.32, P$ $=0.10)$.

\section{Choice Phase}

When allowed to choose between the 2 options, cows spent $9.4 \mathrm{~h} / \mathrm{d}$ lying in the conventional freestall versus $4.1 \mathrm{~h} / \mathrm{d}$ in the alternative stall (Figure $3 ; F_{1,3}=24.89$, $P=0.016)$. Cows also tended to spend more time standing with 2 hooves in the conventional freestalls $\left(0.7 \pm 0.1\right.$ vs. $\left.0.2 \pm 0.1 \mathrm{~h} / \mathrm{d} ; F_{1,3}=9.00, P=0.058\right)$. Cows showed the opposite preference for the amount of time spent standing fully in the stall; cows spent approximately a quarter of an hour standing with 4 hooves in the alternative stalls versus almost no time in the conventional freestalls $(0.24 \pm 0.03$ vs. $0.02 \pm 0.03$ $\left.\mathrm{h} / \mathrm{d} ; F_{1,3}=36.73, P=0.009\right)$.

Cow size had no effect on preference as assessed by any of the response measures.

\section{DISCUSSION}

In the first phase of the study cows were restricted to either the conventional or alternative stall design. The time that cows spent lying down did not vary with treatment, and the average lying time of approximately $13 \mathrm{~h} / \mathrm{d}$ is similar to those observed in previous studies in the same barn and herd (Tucker et al., 2004; Bernardi et al., 2009; Fregonesi et al., 2009a).

Two previous studies reported higher lying times in conventional freestalls than in more open housing systems (Tucker and Weary, 2004; Endres and Barberg, 2007), but other work has found higher lying times in open designs such as straw yards (Phillips and Schofield, 1994; Fregonesi and Leaver, 2002) and sand packs (Fregonesi et al., 2009b). The alternative stall design tested in the current study included a brisket board; this feature is known to reduce stall usage (Tucker et al., 2006).

When provided a choice between the 2 designs, cows in the current study spent more time lying down in the conventional stalls. Previous work has found that cows show a strong preference for lying on softer (Tucker et al., 2003) and more even (Drissler et al., 2005) stall surfaces. We suggest that the hard, protruding edge of the wooden stall dividers used in the current study made this alternative design much less attractive for the cows to lie down. This result suggests that future work should investigate different partition designs, including options that are rounded, softer, and less protruding from the bedded surface of the stall. Previous experience of stalls can also affect cow preference (Tucker et al., 2003). The experimental animals in the current 


\section{a) Lying time}

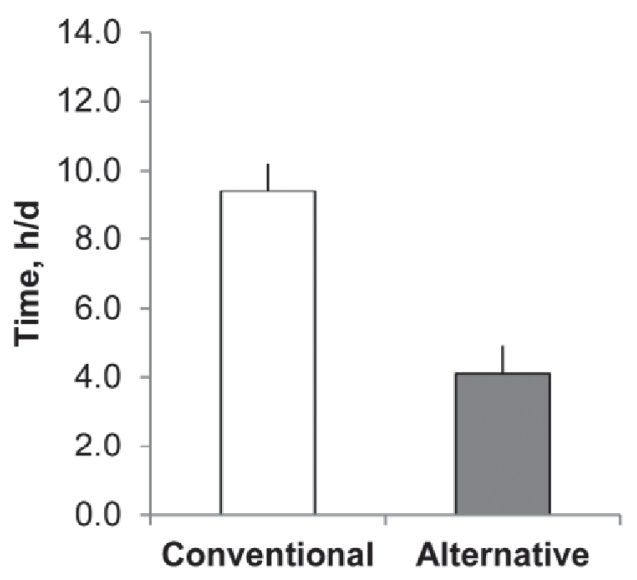

b) Standing - 2 hooves

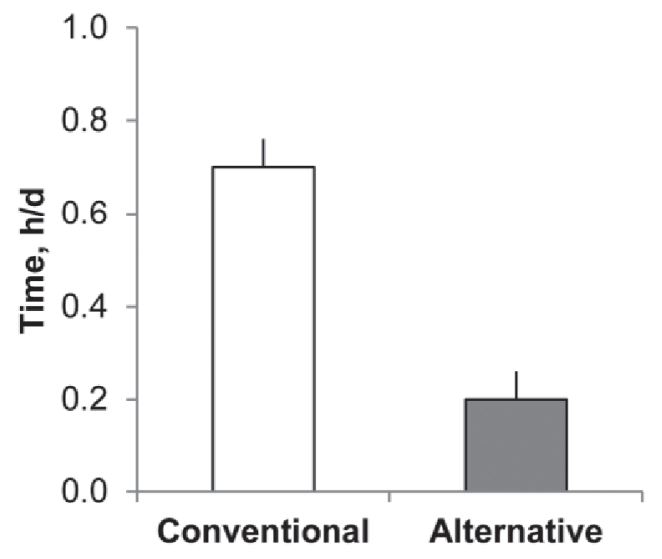

c) Standing - 4 hooves

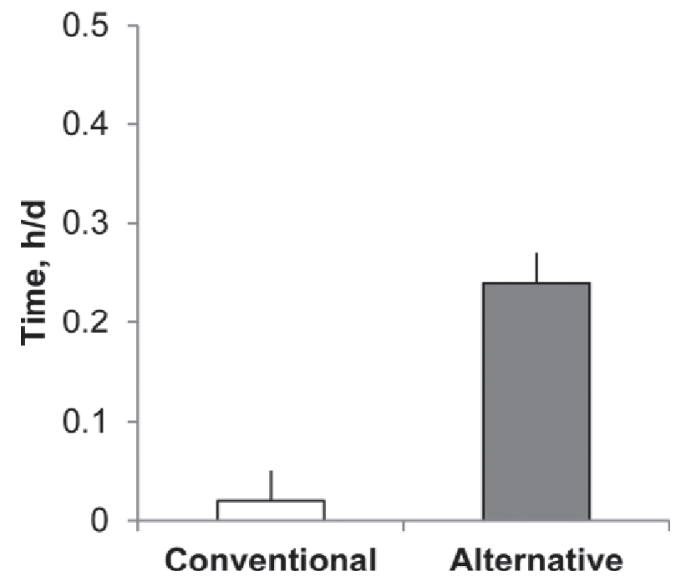

Figure 3. Results from the choice phase during which 4 groups of 12 cows each were provided free access to both conventional and alternative stalls for $7 \mathrm{~d}$. Least squares means $( \pm \mathrm{SE})$ are shown for time $(\mathrm{h} / \mathrm{d}$ ) spent (a) lying down in the stall, (b) standing with front 2 hooves in the stall, and (c) standing with all 4 hooves in the stall. study all had long-term experience with the traditional freestall and only a few days with the alternative stall.

During the no-choice phase, no difference was observed between treatments in time cows spent standing with 2 hooves in the stalls. Previous studies have reported that cows spend less time "perching" in the bedded area when provided less restrictive housing such as an open pack (Fregonesi et al., 2009b) or stalls with the neck-rail positioned higher from the stall surface (Tucker et al., 2005) and further away from the curb (Fregonesi et al., 2009a). It is possible that the wooden boards embedded into the sand surface somehow inhibited perching in the current study, but why this should be the case is not clear. Perching may be a learned behavior related to experience with restrictive stalls earlier in life (Stefanowska et al., 2001; Fregonesi et al., 2009b), suggesting that longer-term studies may be needed.

The neck rail functions to prevent cows from standing too far forward in the stall. Ideally the cow would be positioned such that it could stand comfortably on the dry, clean bedding, but close enough to the rear alley that the feces and urine would fall outside of the stall. In reality, the neck rail is often positioned in such as way that it prevents cows from standing fully in the stall (Fregonesi et al., 2009a), forcing the cow to spend more time standing in the alley and increasing the risk of lameness (Bernardi et al., 2009). Previous studies have found that cows spend more time standing fully in the bedded area when provided larger stalls (Tucker et al., 2005) or an open pack (Fregonesi et al., 2009b). The results of the current study are consistent with these findings, showing that cows spent more time standing fully in the alternative stall than in the conventionally designed freestall. Cows also showed a strong preference for standing fully in the more open stall when they were provided the option during the choice phase of the current study. Cows likely choose to stand in the stall to avoid the concrete flooring and manure slurry in the alley (Stefanowska et al., 2001).

Some previous work has also shown that cows will respond to uncomfortable lying surfaces (such as mattresses) by spending more time standing in the stall (Cook et al., 2004), but in this previous work the increased standing was driven by a decline in time spent lying down. In the current study the increased standing time in the alternative stalls cannot be explained by reduced lying. Instead, this time comes from when cows would be otherwise standing elsewhere in the pen (outside of the stall, and thus on wet concrete known to increase the risk of lameness).

Earlier studies have also examined the effects of stall design on cleanliness of the lying area and cows' udder (Tucker et al., 2005; Bernardi et al., 2009; Ruud 
and Bøe, 2011). Consistent with previous results, the less restrictive stall configuration resulted in more fecal contamination of the stall surface and the cows' udders. As discussed above, allowing cows to stand fully in the stall likely increased the risk of contamination. Clean stalls require less time to maintain the stall surface (Fregonesi et al., 2009a) and to clean the cows' teats in preparation for milking (Bernardi et al., 2009).

Time spent standing fully or partially in the stall is affected by many factors, such as neck rail placement, and stall and cow size (Tucker et al., 2005; Bernardi et al., 2009). In this study the time standing with 2 hooves in the stall was greater in the traditional than in the alternative freestall. A similar observation was found when dairy cows could choose between freestalls and an open-pack (Fregonesi et al., 2009b). Animals may learn to perform this behavior when they are first introduced to freestall housing. Heifers stand with 2 hooves in the stall beginning on the first day they are introduced into the freestall (von Keyserlingk et al., 2011).

In summary, dairy cows preferred to lie down in the traditionally configured freestall versus the more open alternative design tested in the current experiment, but cows preferred the alternative design for standing fully in the stall. These results illustrate that different features of the stall are important for different activities (e.g., a soft, smooth surface for lying, and the lack of dividers and neck-rail for standing), and suggest that a wider range of options needs to be considered in the development of stall designs that function well from both perspectives.

\section{ACKNOWLEDGMENTS}

We thank the faculty, staff, and students at the University of British Columbia's Dairy Education and Research Centre and the University's Animal Welfare Program. M. A. G. von Keyserlingk and D. M. Weary are supported by Canada's Natural Sciences and Engineering Research Council (NSERC) Industrial Research Chair Program with industry contributions from the Dairy Farmers of Canada (Ottawa, ON, Canada), British Columbia Dairy Association (Burnaby, BC Canada), Westgen Endowment Fund (Milner, BC, Canada), Intervet Canada Corporation (Kirkland, QC, Canada), Zoetis (Kirkland, QC, Canada), BC Cattle Industry Development Fund (Kamloops, BC, Canada), Alberta Milk (Edmonton, AB, Canada), Valacta (St. Anne-de-Bellevue, QC, Canada), and CanWest DHI (Guelph, ON, Canada).

\section{REFERENCES}

Bernardi, F., J. Fregonesi, C. Winckler, D. M. Veira, M. A. G. Von Keyserlingk, and D. M. Weary. 2009. The stall-design paradox: Neck rails increase lameness but improve udder and stall hygiene. J. Dairy Sci. 92:3074-3080.

Cook, N. B., T. B. Bennett, and K. V. Nordlund. 2004. Effect of free stall surface on daily activity patterns in dairy cows with relevance to lameness prevalence. J. Dairy Sci. 87:2912-2922.

Cook, N. B., and D. J. Reinemann. 2007. A toolbox for assessing cow, udder, and teat hygiene. Pages 31-43 in Proc. 46th Annu. Mtg. Natl. Mastitis Counc., San Antonio, TX. Natl. Mastitis Counc., Madison, WI.

Drissler, M., M. Gaworski, C. B. Tucker, and D. M. Weary. 2005. Freestall maintenance: Effects on lying behavior of dairy cattle. J. Dairy Sci. 88:2381-2387.

Edmonson, A. J., I. J. Lean, L. D. Weaver, T. Farver, and G. Webster. 1989. A body condition scoring chart for Holstein dairy cows. J. Dairy Sci. 72:68-78.

Endres, M. I., and A. E. Barberg. 2007. Behavior of dairy cows in an alternative bedded-pack housing system. J. Dairy Sci. 90:41924200 .

Flower, F. C., and D. M. Weary. 2006. Effect of hoof pathologies on subjective assessments of dairy cow gait. J. Dairy Sci. 89:139-146.

Fregonesi, J. A., and J. D. Leaver. 2002. Preference of lactating dairy cows or strawyard or cubicle housing systems at two space allowances. Semina Ciências Agrárias 23:45-55.

Fregonesi, J. A., M. A. G. von Keyserlingk, C. B. Tucker, D. M. Veira, and D. M. Weary. 2009a. Neck-rail position in the free stall affects standing behavior and udder and stall cleanliness. J. Dairy Sci. 92:1979-1985.

Fregonesi, J. A., M. A. G. von Keyserlingk, and D. M. Weary. 2009b. Cow preference and usage of free stalls compared with an open pack area. J. Dairy Sci. 92:5497-5502.

Lidfors, L. 1989. The use of getting up and lying down movements in the evaluation of cattle environments. Vet. Res. Commun. 13:307-324.

Phillips, C. J. C., and S. A. Schofield. 1994. The effect of cubicle and strawyard housing on behaviour, production and hoof health of dairy cows. Anim. Welf. 3:37-44.

Ruud, L. E., and K. E. Bøe. 2011. Flexible and fixed partitions in freestalls: Effects on lying behavior and cow preference. J. Dairy Sci. 94:4856-4862.

Schmisseur, W. E., J. L. Albright, C. M. Brown, V. M. Dillon, E. W. Kehrberg, and W. H. M. Morris. 1966. Comparison of free-stall to conventional loose housing. J. Dairy Sci. 49:730.

Stefanowska, J., D. Swierstra, C. R. Braam, and M. M. W. B. Hendriks. 2001. Cow behaviour on a new grooved floor in comparison with a slatted floor, taking claw health and floor properties into account. Appl. Anim. Behav. Sci. 71:87-103.

Tucker, C. B., and D. M. Weary. 2004. Bedding on geotextile mattresses: How much is needed to improve cow comfort? J. Dairy Sci. 87:2889-2895.

Tucker, C. B., D. M. Weary, and D. Fraser. 2003. Effects of three types of free-stall surfaces on preferences and stall usage by dairy cows. J. Dairy Sci. 86:521-529.

Tucker, C. B., D. M. Weary, and D. Fraser. 2004. Free-stall dimensions: Effects on preference and stall usage. J. Dairy Sci. 87:1208-1216.

Tucker, C. B., D. M. Weary, and D. Fraser. 2005. Influence of neck-rail placement on free-stall preference, use, and cleanliness. J. Dairy Sci. 88:2730-2737.

Tucker, C. B., G. Zdanowicz, and D. M. Weary. 2006. Brisket boards reduce freestall use. J. Dairy Sci. 89:2603-2607.

von Keyserlingk, M. A. G., G. E. Cunha, J. A. Fregonesi, and D. M. Weary. 2011. Introducing heifers to freestall housing . J. Dairy Sci. 94:1900-1907. 